\title{
COMPARAÇÃO DA DISPONIBILIDADE DE RADIAÇÃO SOLAR GLOBAL E FOTOPERÍODO ENTRE AS REGIÕES VINÍCOLAS DE CAMPO BELO DO SUL-SC, BRASIL E PECH ROUGE, FRANÇA ${ }^{1}$
}

\author{
HAMILTON JUSTINO VIEIRA², ÁLVARO JOSÉ BACK ${ }^{3}$, APARECIDO LIMA DA SILVA ${ }^{4}$, \\ EMANUELA SALUM PEREIRA ${ }^{5}$
}

RESUMO - Realizaram-se a caracterização e a comparação da disponibilidade de radiação solar global e do fotoperíodo para o Planalto de Santa Catarina, representado por Campo Belo do Sul (latitude -2800'00", longitude $-51^{\circ} 00^{\prime} 00^{\prime}$ " e altitude de 950 metros), e para a região Mediterrânea do Sul da França, representada por Pech Rouge (latitude 4308'35", longitude $03^{\circ} 07^{\prime} 59^{\prime \prime}$ altitude de 1,5 metro). Este estudo foi realizado para a fase de maturação das variedades de videira Chardonnay, Portan, Syrah, Viognier, Carignan, Grenache, Marselan, Mourvèdre e Cabernet Sauvignon. Foram também avaliadas as durações do fotoperíodo anual, do período noturno, da radiação solar global, da radiação solar e da insolação máxima no período de maturação, para ambas as localidades. As diferenças de comportamento fenológico e das posições geográficas dos dois locais promoveram diferenças quanto à disponibilidade e intensidade da radiação solar global, assim como do fotoperíodo. Apesar da uma maior transmissividade da atmosfera para Pech Rouge, o Planalto Catarinense apresentou maior disponibilidade e intensidade de radiação solar durante a fase de maturação da videira. Também, o acúmulo de horas de fotoperíodo foi superior no Planalto Catarinense do que em Pech Rouge. Estas diferenças de disponibilidade de radiação solar e fotoperíodo foram provenientes da menor duração da fase de maturação para Pech Rouge, da declinação solar em relação aos dois locais por ocasião da ocorrência desta fase e da diferença da camada atmosférica resultante da diferença de altitude.

Termos para indexação: videira, radiação solar, fotoperíodo, Vitis vinifera L.

\section{COMPARISON OF GLOBAL SOLAR RADIATION AVAILABILITY AND PHOTOPERIOD BETWEEN WINEMAKING REGIONS OF CAMPO BELO DO SUL, STATE OF SANTA CATARINA IN BRAZIL AND PECH ROUGE IN FRANCE}

\begin{abstract}
Availability of solar radiation and photoperiod were compared between the Plateau of Santa Catarina represented by Campo Belo Sul (latitude $-28^{\circ} 00^{\prime} 00^{\prime \prime}$ longitude $-51^{\circ} 00^{\prime} 00^{\prime \prime}$ and height $1000 \mathrm{~m}$ ), and the Mediterranean region of southern France, represented by Pech Rouge (latitude $43^{\circ} 08^{\prime} 35^{\prime \prime}$, longitude $03^{\circ} 07^{\prime} 59^{\prime \prime}$, height 1.5 meters). The study was conducted for the maturation period of grape varieties Chardonnay, Portan, Syrah, Viognier, Carignan, Grenache, Marselan, Mourvèdre and Cabernet Sauvignon. The annual photoperiod, nighttime duration and global solar radiation, and solar radiation and maximum sunshine during maturation period were evaluated for both locations. Differences in phenological behavior and in geographical position of the two locations resulted in differences on the availability and intensity of solar radiation, as well as on the photoperiod. Despite a higher transmissivity of the atmosphere to Pech Rouge, the Plateau of Santa Catarina showed a higher availability and intensity of solar radiation during the maturation period of grapes. The accumulation of photoperiod was higher in the Plateau of Santa Catarina compared to Pech Rouge. These differences were caused by the shorter duration of the maturation phase in Pech Rouge, by the solar declination for both locations during the maturation period and by the unequal atmospheric layer in different altitudes.
\end{abstract}

Index terms: grapevine, solar radiation, photoperiod, Vitis vinifera.

\footnotetext{
'(Trabalho 052-11). Recebido em: 12-01-2011. Aceito para publicação em: 08-07-2011.

${ }^{2}$ Ph.D., Bolsista da Capes. Pesquisador da Epagri/Ciram, 1347, C.P. 502, CEP 88034-901.Florianópolis - SC, fone (48) $3239-8064$. E-mail: vieira@epagri.sc.gov.br

${ }^{3}$ PhD., Professor da UFSC/CCA. E-mail: alsilva@cca.ufsc.br

${ }^{4}$ Dr., Pequisador da Epagri, Professor da Unesc. E-mail:ajb@epagri.sc.gov.br;

${ }^{5}$ BS., PesquisadoraＥpagri/Ciram. E-mail: manu@epagri.sc.gov.br
} 


\section{INTRODUÇÃO}

Os maiores produtores mundiais de vinho são a França, Itália, Espanha e EUA. Contudo, com o processo de globalização, a ameaça das mudanças climáticas à qualidade das uvas e vinhos das regiões tradicionais e a consciência mercadológica de que os produtos vinícolas são uma oportunidade de desenvolvimento regional, quer seja pela exportação, quer pelo desenvolvimento enoturístico, novas regiões vitícolas estão desenvolvendo-se e tomando importância no mercado internacional. Para os países já estabelecidos no comércio internacional de bebidas vinificadas, surge a preocupação de que os países emergentes possam vir a ofertar vinhos finos com preço concorrente àqueles produzidos pelos países tradicionais (JONES, 2006; STOCK et al., 2007). Neste contexto, o Brasil, denominado como "novo-novo" no que tange ao seu possível surgimento no mercado internacional, já é incluído como caso de estudos, quer seja pela sua extensão territorial, quer pelas condições climáticas variáveis, apresentando assim grande potencial de produção de uvas e vinhos finos (CCE, 2009). A vitivinicultura de Santa Catarina mostra-se promissora pelas condições climáticas determinadas pela sua posição geográfica e suas elevadas altitudes, no entanto a produção de uvas viníferas nas regiões de altitudes mais elevadas em Santa Catarina ainda é recente (FALCÃO et al., 2008; FALCÃO et al., 2010). Devido ao pequeno intervalo de tempo de implantação, crescimento e desenvolvimento da viticultura nas regiões do Planalto Catarinense, as pesquisas agrometeorológicas nesta cultura ainda são incipientes, e o entendimento do desempenho da cultura frente estas condições edafoclimáticas é um fator decisivo para a produção de vinhos de qualidade. Esta denominação de Planalto Catarinense, no caso da viticultura, abrange todos os municípios entre 800 e 1.400 metros de altitude (FALCÃO et al., 2008).

Atualmente, na França, um dos países que desenvolveu metodologias e promoveu as discussões pertinentes, procurando difundir esta cultura e o sistema de proteção de produtos agroindustriais, possui cerca de 340 processos reconhecidos de proteção de produtos agropecuários vinculados ao "saber fazer" e aos territórios ("terroir"). Paralelamente aos estudos e processos de reconhecimento e delimitação de áreas com características climáticas homogêneas, existem numerosos estudos de regionalização das regiões vitícolas e suas relações com a ecofisiologia desta cultura, principalmente com a temperatura do ar. Dentre estes estudos, podem ser citados os trabalhos de Falcão et al. (2008), Lopes et al. (2008) e de Orlandini et al. (2009). Uma variável decisiva do desempenho da videira e da qualidade da uva é a radiação solar. É um dos fatores primários que influencia na temperatura, evapotranspiração, umidade do solo e umidade atmosférica, entre outros (CARRASCO et al., 2008). Diretamente, por sua vez, atua sobre a concentração de açúcares e a coloração das bagas (KENNEDY, 2008). Já a temperatura é responsável pela atenuação do ácido málico e da acidez do mosto. Somente com condições apropriadas de radiação solar e temperatura é que a videira ganha a maturação desejada.

No Brasil, as pesquisas agronômicas com a cultura da videira e sua interação com a disponibilidade da radiação solar vêm sendo realizadas no campo da micrometeorologia. Para subsidiar as futuras pesquisas agronômicas, agrometeorológicas e as comparações entre as bebidas vinificadas em Santa Catarina e, quiçá, no Brasil, realizaram-se a caracterização e a comparação da disponibilidade de radiação solar global entre o Planalto de Santa Catarina, uma nova e promissora região produtora de vinhos, e a região mediterrânea do sul da França. Esta região francesa, denominada Languedoc-Roussillon, é uma das áreas vitícolas contíguas mais extensas do mundo, e foi representada neste trabalho pelas condições climáticas de Pech Rouge. Esta região possui alta disponibilidade de radiação solar e longos fotoperíodos.

\section{MATERIAL E MÉTODOS}

Para os estudos comparativos, utilizaram-se os dados fenológicos e meteorológicos da unidade experimental do INRA-"Institut National de La Recherche Agronomique" de Pech Rouge (latitude $43^{\circ} 08^{\prime} 35^{\prime \prime}$, longitude $-3^{\circ} 07^{\prime} 59^{\prime \prime}$ e altitude de 1,5 metro). Nos estudos para Santa Catarina, localizada entre os paralelos $-25^{\circ} 57^{\prime} 41^{\prime \prime}$ e $-29^{\circ} 23^{\prime} 55^{\prime}$ " de latitude e entre os meridianos $-48^{\circ} 19^{\prime} 37^{\prime \prime}$ e $-53^{\circ} 50^{\prime} 00^{\prime \prime}$ de longitude, utilizou-se um ponto médio para o Planalto Catarinense com latitude de $-28^{\circ} 00^{\prime} 00^{\prime \prime}$, longitude $-51^{\circ} 00^{\prime} 00^{\prime \prime}$ e altitude de 1.000 metros.

A radiação solar global foi proviniente dos bancos de dados da Epagri-SC e da unidade experimental do INRA-Pech Rouge do sul da França. Para os cálculos da radiação solar global extraterrestre, utilizou-se a metodologia descrita por Allen et al. (1998), em que a radiação solar global é calculada por:

$$
R a=\left(\frac{0,0864}{\pi}\right) G s E o(W s \cdot \operatorname{sen} \phi \cdot \operatorname{sen} \delta+\cos \phi \cdot \cos \delta \cdot \operatorname{sen} W s)
$$


$\mathrm{Ra}=$ radiação solar no topo da atmosfera $\left(\mathrm{MJ} \mathrm{m}^{-2}\right.$ $\left.\operatorname{dia}^{-1}\right)$;

$\mathrm{Gs}=$ constante solar média Gs $=1367\left(\mathrm{~W} \mathrm{~m}^{-2}\right)$;

Eo $=$ fator de correção da excentricidade da órbita terrestre;

Ws $=$ duração do dia solar (rad);

$\delta=$ declinação solar $(\mathrm{rad})$;

$\phi=$ latitude do local (rad).

O fator de correção da excentricidade da órbita terrestre é dado por:

$$
E o=\left(\frac{D_{T S}}{D m}\right)^{2}
$$

em que: $\mathrm{D}_{\mathrm{TS}}=$ distância da Terra ao Sol;

$\mathrm{Dm}=$ distância média da Terra ao Sol.

Chamando Eo de distância relativa $\left(\mathrm{d}_{\mathrm{r}}\right)$, pode-se estimá-la como:

$$
d_{r}=1+0,033 \cos \left(\frac{2 \pi}{365} J\right)
$$

em que: $\mathrm{J}=$ dia do ano [0 a 364].

A insolação máxima teórica é expressa pela equação:

em que:

$$
N=\frac{24}{\pi} \omega_{s}
$$

$\mathrm{N}$ = insolação máxima teórica (horas);

$\omega_{\mathrm{s}}=$ ângulo do pôr do sol (rad.), estimado

por:

$$
\omega_{s}=\arccos (-\tan \phi \tan \delta)
$$

Os dados fenológicos usados neste trabalho foram provenientes das observações da Epagri, UFSC/RGV e das vitivinícolas Grando e Vila Francioni, nos vinhedos situados nos municípios de Campos Novos, Campo Belo do Sul, São Joaquim, Videira, Água Doce e do INRA-Pech Rouge, considerando as variedades: Chardonnay, Portan, Syrah, Viognier, Carignan, Grenache, Marselan, Mourvèdre e Cabernet Sauvignon.

\section{RESULTADOS E DISCUSSÃO}

O início de maturação (Pintor) para as variedades utilizadas ocorre em Pech Rouge, cerca de 20 a 30 dias após o solstício de verão, enquanto para o Planalto Catarinense essa fase ocorre de 40 a 70 dias depois do solstício (Figura 1). Os valores de 10 a 20 dias após o solstício do Planalto Catarinense foram observados no município de Videira, com altitude de 700 metros. A diferença média entre o Planalto Catarinense e Pech Rouge para essa fase é em torno de 40 dias. Para a região do Planalto Catarinense, corresponde ao início de fevereiro, e para Pech Rouge, corresponderia ao início de janeiro.

A maturação para Pech Rouge ocorre aproximadamente 78 dias após o solstício de verão (Figura 2), o que corresponderia ao início de março para o Hemisfério Sul, enquanto para o Planalto Catarinense a maturação fisiológica ocorre cerca de 120 dias após o solstício de verão, ou aproximadamente em final de abril. Considerando esses valores médios, observamos que a diferença da ocorrência dessa fase é em torno de 40 dias, mantendo a diferença entre os locais como no caso do início da maturação.

Considerando-se essas duas fases, nota-se que a diferença entre as duas regiões é concernente ao período em que ocorrem. Ou seja, a fase de maturação da videira no Planalto Catarinense posterga-se cerca de quarenta dias em relação à região do Mediterrâneo. Esse deslocamento temporal é provavelmente em função da temperatura mais elevada de Pech Rouge, assim como da maior disponibilidade de radiação solar nas fases anteriores à da maturação para esse mesmo local. Essas diferenças são devidas às características varietais e pela influência do meio ambiente, tais como: radiação solar, fotoperíodo, temperatura e disponibilidade de água. Apesar de um deslocamento temporal de cerca 40 dias, considerando-se a fase de início de maturação e a de maturação, nota-se, na Figura 3, que a duração dessa fase possui uma duração com menos variabilidade. Enquanto para Pech Rouge, a duração em dias é de cerca de 50 dias, para o Planalto Catarinense é de 70 dias. A diferença entre elas é de cerca de 20 dias. Nesse aspecto, pode-se afirmar que a influência do clima é sobre o período de ocorrência das fases e menor na duração das fases.

Esse comportamento das fases fenológicas da videira tem sido relatado por inúmeros autores, como Lüers (2003), que fez um estudo com dados de 20 anos para o Vale do Rio Reno, mostrando uma antecipação das fases de maturação de cerca de 10 dias. Em Maringá - PR, para a variedade Cabernet Sauvignon, a diferença anual dessa fase foi de 52 e 36 dias (JUBILEU et al., 2010) para dois anos de estudos. Lopes et al. (2008) determinaram uma diferença de 49 dias entre as diversas observações do período de maturação. Para verificar a disponibilidade da radiação solar para a cultura da videira frente a essa variabilidade de ocorrência das fases fenológicas e sua duração, efetuou-se a comparação entre radiação solar global para as duas regiões. $\mathrm{Na}$ Figura 4, observa-se a incidência da radiação solar global para as duas regiões. No período de inverno, a disponibilidade de radiação solar para o Planalto Catarinense é superior à região de Pech Rouge. Nos meses de outono e primavera, a diferença da disponibilidade de radiação solar entre os locais apresenta uma tendência de se igualarem. Já nos meses de ve- 
rão, a incidência de radiação solar é maior para Pech Rouge. Nota-se também que a variabilidade diária de radiação solar é maior para o Planalto Catarinense.

A intensidade de radiação solar global, durante os meses de inverno, é menor para Pech Rouge, como pode ser observado na Figura 5. Esses menores valores são explicados pela declinação solar que, nos meses de inverno, é de $-23^{\circ} 27^{\prime}$, situando-se Pech Rouge a uma latitude de $43^{\circ} 08^{\prime}$. Nessa circunstância, a incidência da radiação solar ocorre com um ângulo de declinação equivalente a $66^{\circ} 40^{\prime}$. Para os meses invernais no Planalto Catarinense, com uma latitude média de $-28^{\circ}$, a declinação solar é de $23^{\circ} 27^{\prime}$. A inclinação da radiação é equivalente a $51^{\circ} 27^{\prime}$. Comparando-se essas duas datas, verificamos que os raios solares incidem em Pech Rouge com ângulo de inclinação de cerca de $15^{\circ}$ superiores ao Planalto Catarinense. Nos meses de outono e primavera, os dois locais mostram uma equivalência na intensidade de radiação, e nos meses de verão, as intensidades médias de radiação (Figura 6) são maiores em Pech Rouge. Por ocasião dos meses de verão, tomando como referência o valor absoluto de $23^{\circ} 27^{\prime} \mathrm{e}$ as latitude dos locais, obtém-se para Pech Rouge a inclinação da incidência da radiação solar com cerca de $20^{\circ}$. Para o Planalto Catarinense, a inclinação dos raios solares incidentes é de $\left(23^{\circ} 27^{\prime}\right.$ $-28^{\circ}=3^{\circ}$ ) cerca de $3^{\circ}$.

Na Figura 6, estão dispostos os valores médios mensais de radiação solar medidos em Campo Belo do Sul e Pech Rouge. Pelas médias mensais, verifica-se que a variação da radiação solar para Pech Rouge possui uma semelhança com as radiações extraterrestres apresentadas para os dois locais, na Figura 5. Para Pech Rouge, a radiação solar mensal pode ser representada pela equação polinomial de quarta ordem, relacionando os meses e os valores médios mensais da radiação medida de acordo com:

Para Pech Rouge:

$$
\mathrm{Rg}=0,7408 \mathrm{x}^{4}-18,758 \mathrm{x}^{3}+135,95 \mathrm{x}^{2}-
$$

$220,93 \mathrm{x}+300,95 \quad\left(\mathrm{R}^{2}=0,9936\right)$

Para o Planalto Catarinense esta equação é: $\operatorname{Rg}=0,3857 \mathrm{x}^{4}-9,9569 \mathrm{x}^{3}+73,404 \mathrm{x}^{2}-$ $122,17 \mathrm{x}+410,11 \quad\left(\mathrm{R}^{2}=0,9475\right)$

em que: " $x$ " são os meses do ano, e "Rg" as médias mensais da radiação global.

Nota-se uma depleção na curva representativa para Campo Belo do Sul, que ocorre nos meses 7 e 8, correspondentes aos meses janeiro e fevereiro. Este comportamento está ligado à nebulosidade destes meses em comparação com os demais.

Apesar desta maior inclinação dos raios solares, um maior comprimento dos dias para Pech Rouge e ainda a altitude de 1,5 metro acima do mar e cerca de 950 metros para o Campo Belo do Sul, na região central do Planalto Catarinense, a intensidade é maior em Pech Rouge. Esta maior intensidade de radiação solar pode ser explicada pela menor umidade atmosférica e menor nebulosidade observada em Pech Rouge. No Planalto Catarinense, o valor da precipitação média mensal é de 150 milímetros, enquanto em Pech Rouge estes valores ficam ao redor dos 40 milímetros no inverno e cerca de 10 milímetros no verão e primavera. Estes valores de maior intensidade de radiação solar para Pech Rouge são, em suma, devido à maior transmissividade da atmosfera, que para Pech Rouge fica em torno de $60 \%$, e para o Planalto Catarinense em torno de $45 \%$. Na maioria dos meses, a transmissividade da atmosfera no Planalto Catarinense é inferior à de Pech Rouge (Figura 7); em alguns meses, essa diferença pode chegar próximo de $10 \%$. Para os dois locais, os meses invernais mostram uma semelhança entre si em relação à transmissividade, na ordem de $50 \%$. Estes valores são concordantes com aqueles determinados por Almorox et al. (2008) para latitudes entre $6^{\circ} 00^{\prime}$ à $11^{\circ} 25^{\prime}$ e longitudes oeste de $61^{\circ} 27^{\prime}$ a $71^{\circ} 44^{\prime}$ da Venezuela. Conceição e Mandelli (2006) citam uma transmissividade média de cerca 0,5 para Bento Gonçalves (latitude $-29^{\circ} 09^{\prime}$ e altitude de 640 metros), enquanto Dornelas et al. (2006) relatam uma transmissividade diária de 0,2 a 0,7 para Brasília-DF (latitude 1556' e altitude de 997 metros).

Apesar das diferenças de latitude, altitude e demais fatores que interferem na transmissividade atmosférica, os dois locais apresentam valores anuais acumulados equivalentes à radiação solar global acumulada no período de um ano, com valor em torno de $4.500 \mathrm{MJ} . \mathrm{m}^{-2}$, como pode ser visualizado na Figura 8 . Nos meses primaveris, o Planalto Catarinense apresenta valores um pouco superiores e, nos meses de verão e outono, essa situação se inverte. Por outro lado, são observadas diferenças na radiação solar global acumulada no período entre o início da maturação e o final da maturação. Enquanto Pech Rouge apresenta uma radiação acumulada de $456 \mathrm{MJ} \cdot \mathrm{m}^{-2}$, o Planalto Catarinense acumula 1.076 MJ. $\mathrm{m}^{-2}$ (Figura 9), ou seja, $136 \%$ superior. A diferença entre os locais é resultante dos períodos de ocorrência do início e final de maturação, assim como pela duração desta fase.

Na Figura 10, são apresentados os somatórios das horas da duração do dia para os dois locais. Neste caso, as diferenças entre eles, em relação ao número de horas de incidência de radiação entre o pôr e nascer do Sol é de 22,6\%. Considerando que estes valores são superiores aos da radiação solar incidente, conclui-se que a intensidade da radiação solar para o Planalto Catarinense é superior àqueles de Pech Rouge, frente às épocas de maturação consideradas. 
Para Pech Rouge, o total de horas acumulado é de 715, enquanto para o Planalto Catarinense é de 877 horas, sendo a diferença de 162 horas. A incidência da radiação solar nos cachos de uva também contribui para ativar o metabolismo e a formação de substâncias responsáveis pela qualidade do vinho, como os compostos fenólicos, especialmente as antocianinas e os taninos (MIELE et al., 2009). Essa diferença pode conferir aos vinhos do Planalto Catarinense uma coloração mais intensa, com aroma mais rico, de maior volume em boca, equilibrados em álcool e acidez, de sabor complexo e persistente (ZANUS; MANDELLI, 2004).

Contudo, o desempenho da videira frente à disponibilidade de radiação solar e sua intensidade não podem ser considerados como único fator a ser avaliado. Se, por um lado, Pech Rouge possui menor quantidade e intensidade de radiação solar durante a fase de maturação, possui menor período noturno disponível para a respiração da videira, em torno de 456 horas (Tabela 1). Para Campo Belo do Sul, essa duração é de 792 horas, sendo a diferença entre os dois locais de 336 horas. A relação entre a duração do fotoperíodo e o período noturno acumulado durante a maturação para Pech Rouge é de 1,68, e para Campo Belo do Sul, 1,18. Esse maior acúmulo de horas noturnas em Campo Belo do Sul pode diminuir o acúmulo de sólidos solúveis por aumentar o período de respiração noturna. Conforme Falcão et al. (2010), o clima da região do Planalto Catarinense favorece o acúmulo de sólidos solúveis e uma notável intensidade de coloração das uvas e vinhos resultantes do acúmulo de antocianinas.

As mudanças climáticas previstas para as próximas décadas induzem a previsões de antecipação das colheitas, principalmente para o Hemisfério Norte (SEGIN, 2007; STOCK et al., 2007; LEGAVE et al., 2009; LEGAVE, 2009). Com o deslocamento das fases fenológicas, ou seja, a antecipação das colheitas, a tendência é aumentar a disponibilidade e a intensidade da radiação solar, assim como maior disponibilidade de horas de luminosidade, consequentemente com menor mudança da incidência da radiação solar no Hemisfério Sul. Naturalmente, a questão do potencial genético (LOUARN et al., 2008), o manejo da arquitetura foliar e o dossel vegetativo podem modificar o aproveitamento da radiação solar pela cultura (SEGIN, 2007; MANDELLI et al., 2008; MIELE et al., 2009; FAVERO et al., 2010).

TABELA 1- Resumo das variáveis utilizadas para a comparação entre Pech Rouge, no Sul da França, e para Campo Belo do Sul, no Planalto Catarinense - Brasil.

\begin{tabular}{lcc}
\hline \multirow{2}{*}{ Variável } & \multicolumn{2}{c}{ Local } \\
\cline { 2 - 3 } & Pech Rouge & Campo Belo do Sul \\
\hline Latitude & $43^{\circ} 08^{\prime} 35$ & $28^{\circ} 00^{\prime} 00^{\prime \prime}$ \\
Altitude (m) & 1,5 & 950 \\
Início da maturação após solstício de verão (dias) & 25 & 50 \\
Variação final da maturação (dias) & 78 & 119 \\
Duração do período entre início da maturação e maturação (dias) & 50 & 68 \\
Fotoperíodo anual (horas) & 767 & 936 \\
Período Noturno (horas) & 456 & 792 \\
Relação Fotoperíodo/Período noturno & 1,68 & 1,18 \\
Transmissividade da atmosfera & 0,55 & 0,48 \\
Radiação solar global (MJ m ${ }^{-2}$ ano $\left.{ }^{-1}\right)$ & 4500 & 4500 \\
Radiação solar no período de maturação $\left(\mathrm{MJ} \mathrm{m}^{-2}\right)$ & 456 & 1076 \\
Insolação máxima no período de maturação $(\mathrm{h})$ & 715 & 877 \\
\hline
\end{tabular}




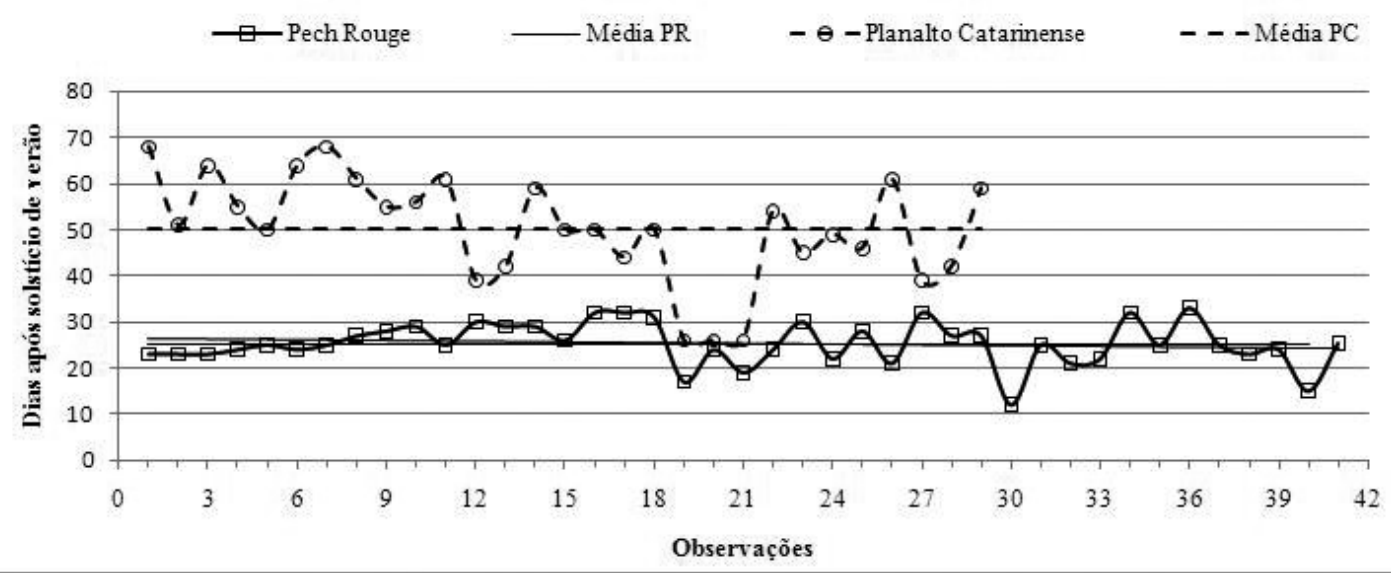

FIGURA 1 - Variação do início de maturação, em dias, após o solstício de verão para diversas variedades e anos para as localidades de Pech Rouge, sul da França, e no Planalto Catarinense.

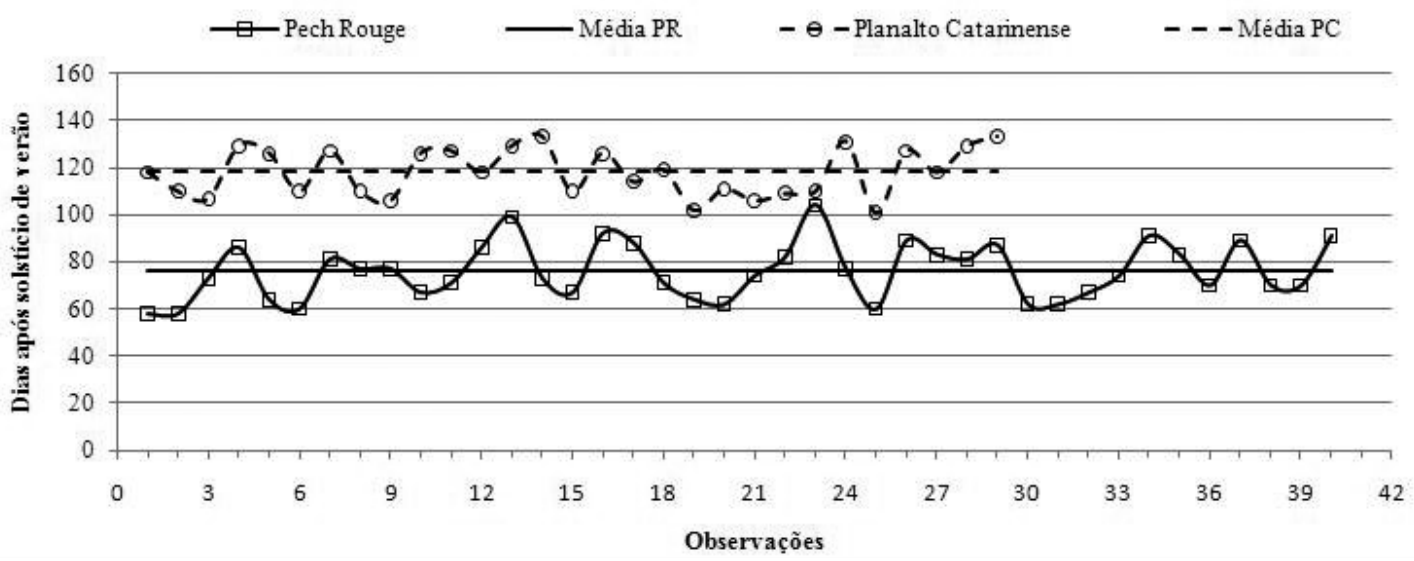

FIGURA 2- Variação do final de maturação, em dias, após o solstício de verão para diversas variedades e anos para as localidades de Pech Rouge, sul da França, e no Planalto Catarinense.

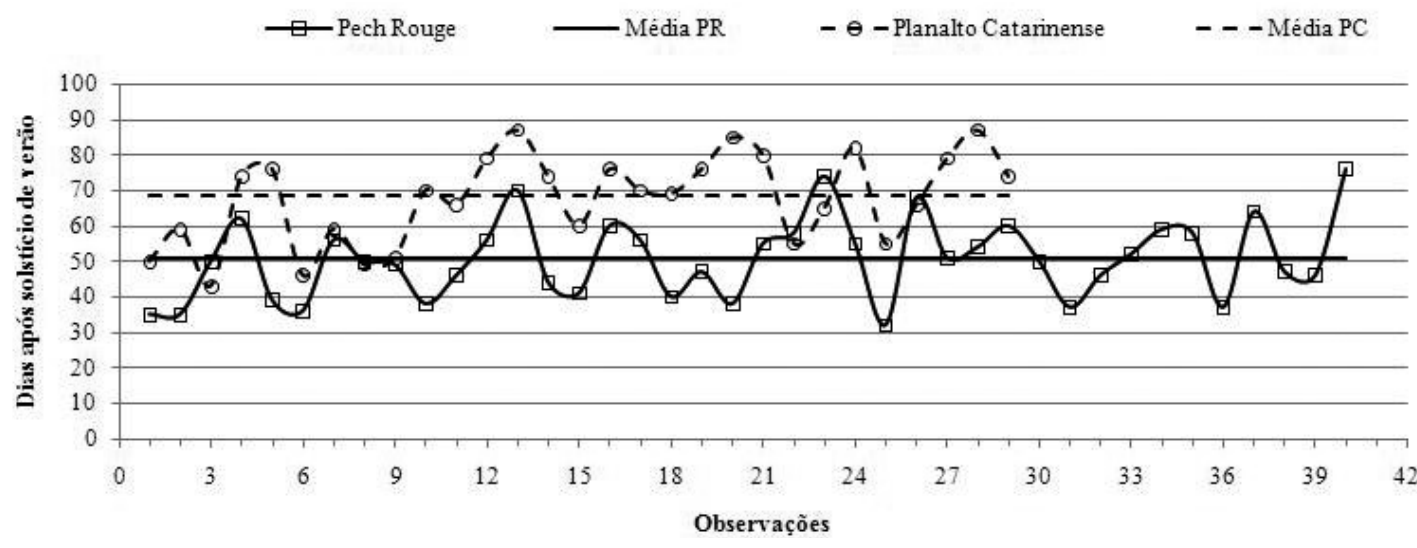

FIGURA 3- Variação da duração, em dias, da fase fenológica entre o início da maturação (pintor) e a maturação, para diversas variedades e anos, para as localidades de Pech Rouge, sul da França, e no Planalto Catarinense. 


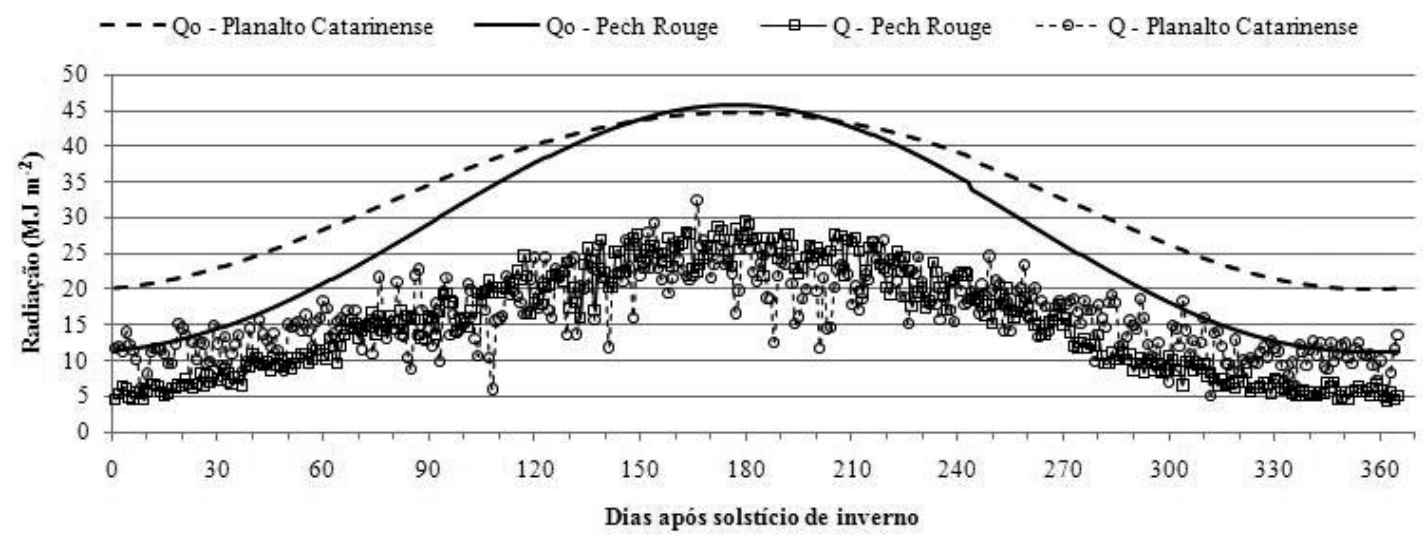

FIGURA 4 - Variação anual da radiação solar global diária extraterrestre (Qo), e radiação solar global diária (Q) medida em Pech Rouge, no sul da França, e no Planalto Catarinense.

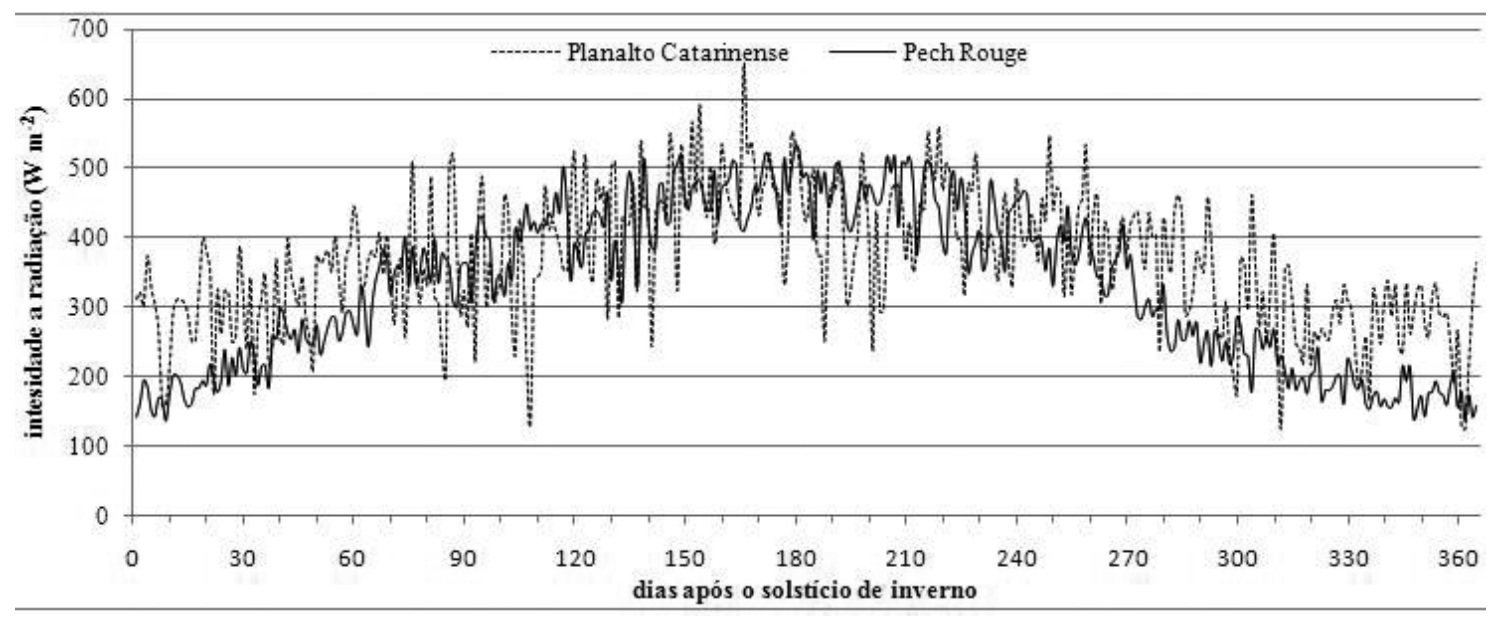

FIGURA 5 - Variação anual da intensidade da radiação solar global diária extraterrestre medida em Pech Rouge, no sul da França, e no Planalto Catarinense.

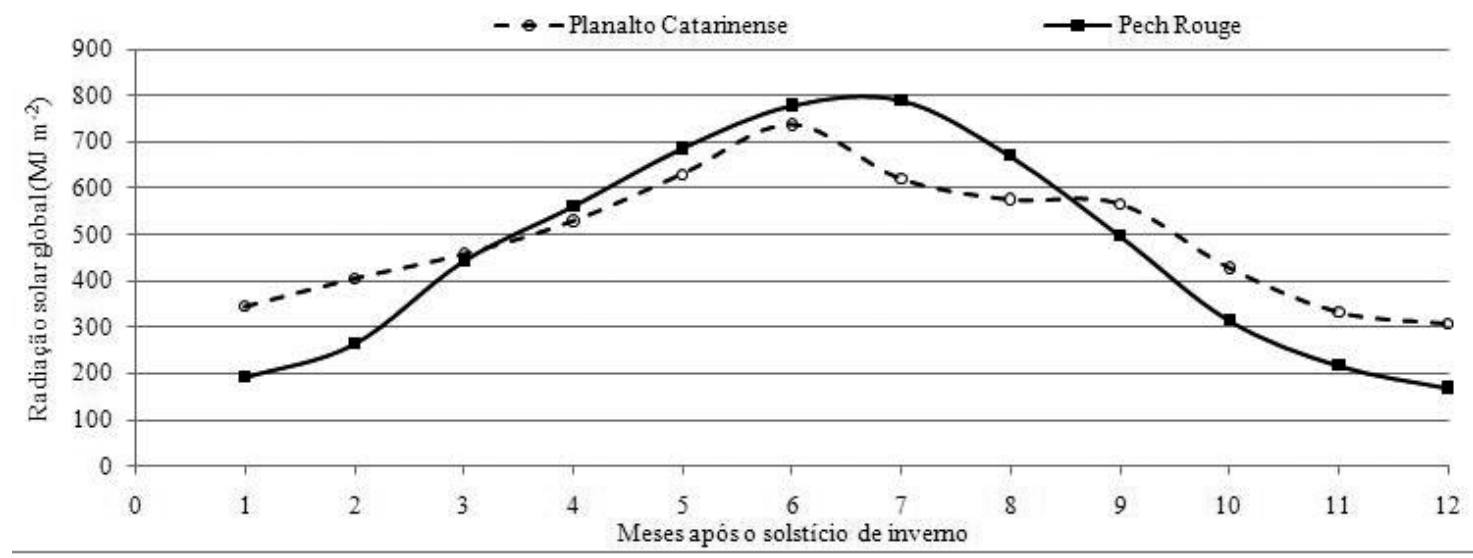

FIGURA 6 - Variação da média mensal da radiação solar global diária extraterrestre em Pech Rouge, no sul da França, e no Planalto Catarinense. 


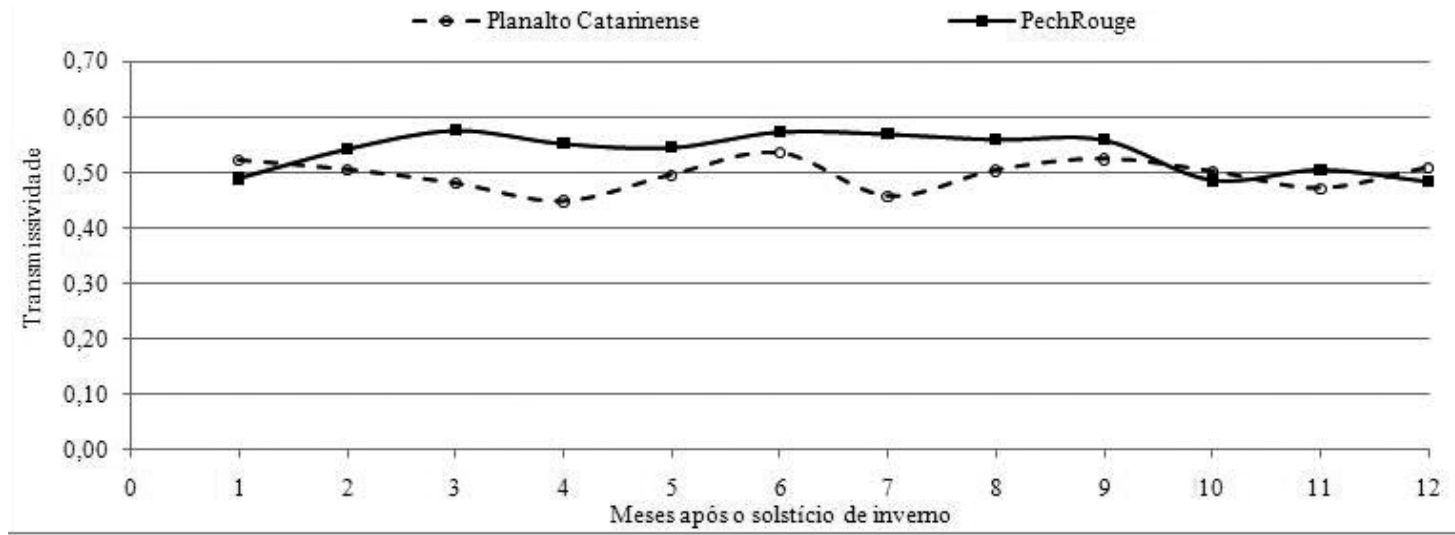

FIGURA 7 - Variação da média mensal da transmissividade atmosférica para Pech Rouge, no sul da França, e no Planalto Catarinense.

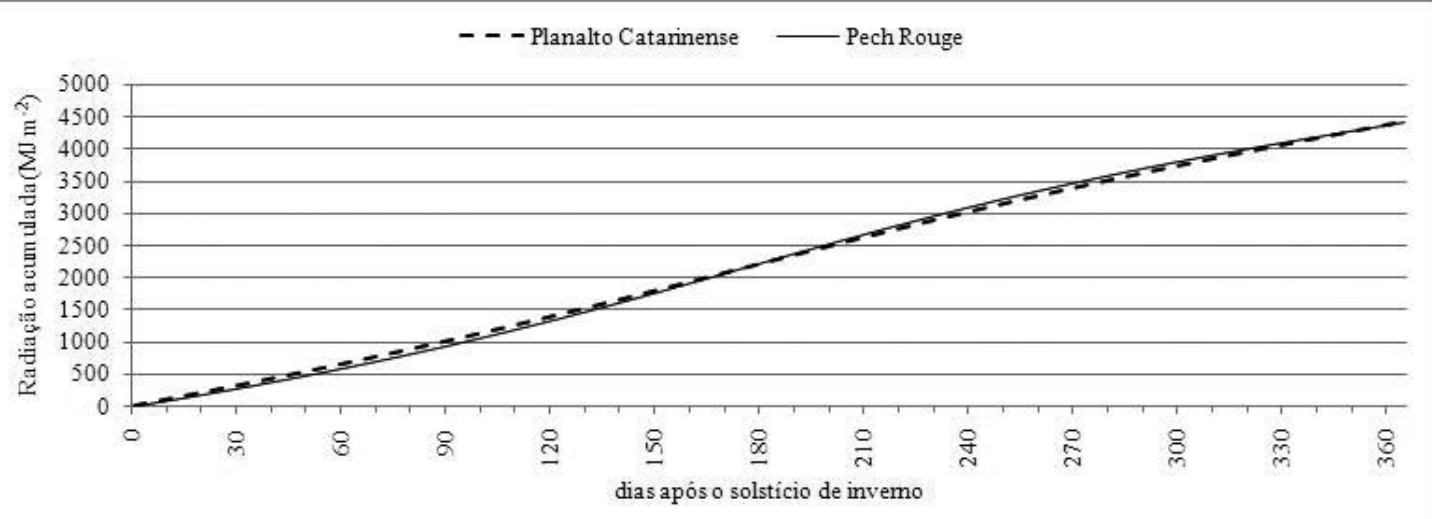

FIGURA 8 - Radiação solar global acumulada no período anual medida em Pech Rouge, no aul da França, e no Planalto Catarinense.

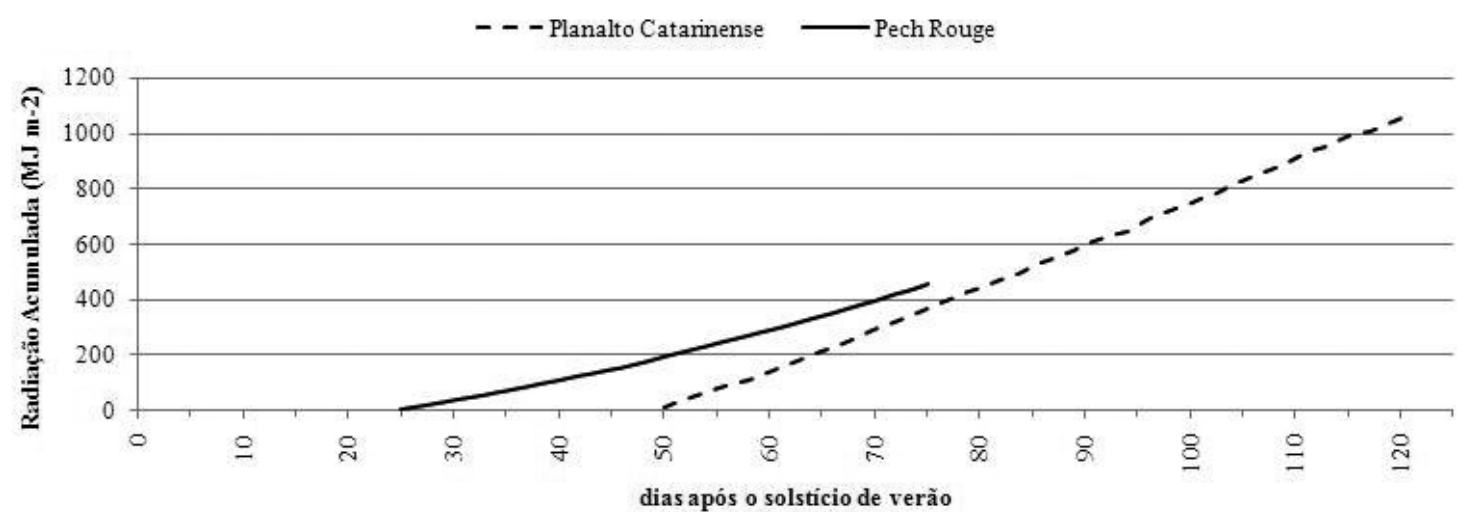

FIGURA 9 - Radiação solar global acumulada no período de maturação da videira medida em Pech Rouge, no sul da França (setembro a outubro), e março a abril no Planalto Catarinense. 


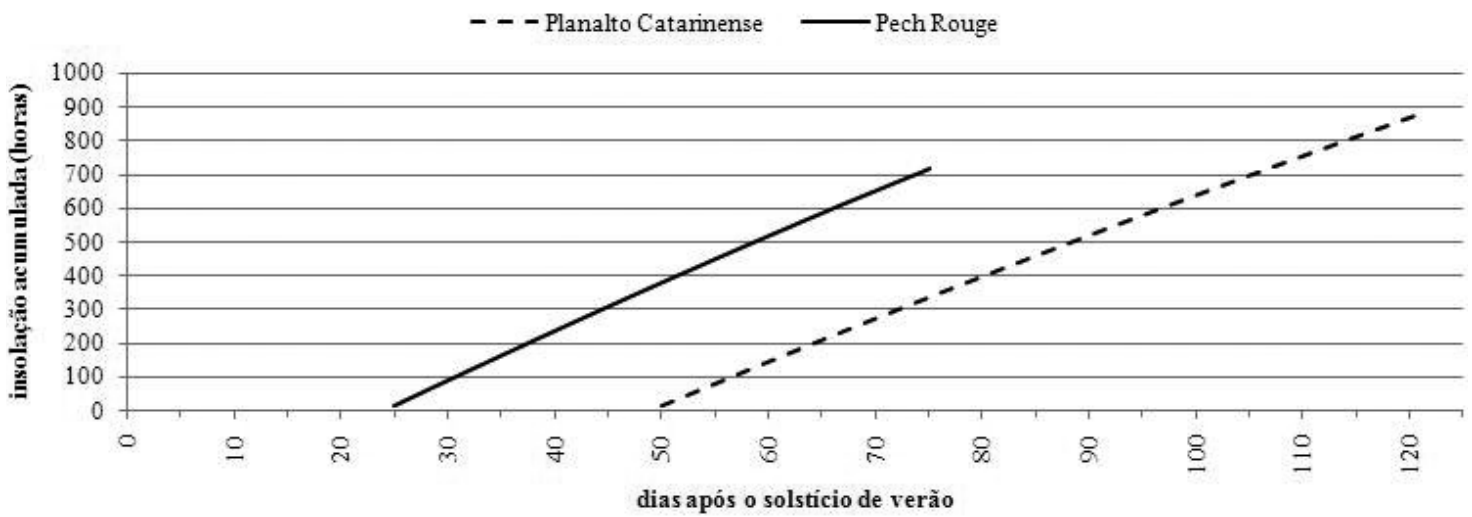

FIGURA 10 -Insolação máxima teórica acumulada (horas) durante o período compreendido entre o início de maturação e a colheita da cultura da videira para Pech Rouge, no sul da França, e no Planalto Catarinense.

\section{CONCLUSÕES}

As fases fenológicas da videira apresentam diferenças quanto à duração e quanto ao período do ano de ocorrência destas fases. Para a fase de maturação das uvas, há diferenças de intensidade, quantidade e duração do fotoperíodo entre Pech Rouge, no sul da França, e entre Campo Belo do Sul, no Planalto Catarinense. A variação da radiação solar e da duração do fotoperíodo são consequência dos períodos do ano em que ocorrem as fases de maturação, da duração desta fase, assim como da posição geográfica dos locais, que interfere na incidência dos raios solares. Além das diferenças de radiação solar e da sua intensidade oriundas da variabilidade temporal, quer seja diária, quer seja mensal ou anual, outros fatores interferem na disponibilidade da radiação solar global para a cultura da videira. A localização dos vinhedos, particularmente relacionados com a altitude e longitude, e as características fenológicas associadas às condições térmicas proporcionam diferenças quanto à quantidade e à intensidade da radiação solar disponível. Para a região do Planalto Catarinense, representada por Campo Belo do Sul, ocorre maior acúmulo e intensidade de radiação solar global durante a fase de maturação, em comparação com Pech Rouge. Esse quadro poderá favorecer maior intensidade da coloração da uva no Planalto Catarinense em relação à Pech Rouge. Por outro lado, no Planalto Catarinense, as horas acumuladas nos períodos noturnos foram maiores do que aquelas do Sul da França, representado por Pech Rouge.

\section{AGRADECIMENTOS}

Agradecemos à CAPES, EPAGRI, UFSC, à UFRJ, Univ. de Lyon 2 e ao CIRAD - UMR Innovation, no quadro do projeto cofecub 649/2009, que permitiram a realização deste trabalho.

\section{REFERÊNCIAS}

ALLEN, R. G.; PEREIRA, L. S.; RAES, D.; SMITH, M. Crop evapotranspiration: Guidelines for computing crop water requirements. Rome: FAO, 1998. Irrigation and drainage paper 56.

ALMOROX, J.; BENITO, M.; HONTORIA, C. Estimación de la radiación solar global en Venezuela. INCI, Caracas, v.33, n.4, p.280-283, 2008.

CARRASCO, M.; ORTEGA-FARIAS, S. Evaluation of a model to Simulate Net Radiation Over a Vineyar cv. Cabernet Sauvignon. Chilean Journal of Agricultural Research, Chillán, v.68, n.2, p.156165, 2008.

COMITÈ NATIONAL DES CONSEILLERS DU COMMERCE EXTERIEUR DE LA FRANCE. Le vin dans Le monde à l'horizon 2050. Les enjeux de marché du $21^{\text {ème }}$ siècle. Prospectives. INRA. 2009. 30p.

CONCEIÇÃO, M. A. F.; MANDELLI, F. Estimativa diária da radiação solar incidente com base no número de horas de brilho solar para a região de Bento Gonçalves-RS. Bento Gonçalves: Embrapa Uva e Vinho, 2006. 12p. (Boletim de Pesquisa e Desenvolvimento, 12) 
DORNELAS, K. D.; SILVA da, C. L.; OLIVEIRA, C. A. da S. Coeficientes médios da equação de Angström-Prescott, radiação solar e evapotranspiração de referência em Brasília. Pesquisa Agropecuária Brasileira, Brasília, v.41, n.8, p.1213-1219, 2006.

FALCÃO, L. D.; BURIN, V. M.; CHAVES, E. S.; VIEIRA, H. J.; BRIGHENTI, E.; ROSIER, J. P.; BORDIGNON-LUIZ, M. T. Vineyard altitude and mesoclimate influences on the phenology and maturation of Cabernet-Sauvignon grapes from Santa Catarina State. Journal International des Sciences de la Vigne et du Vin, Villenave d'Ornon, v.44, n.3, p.135-150, 2010.

FALCÃO, L. D.; CHAVES, E. S.; BURIN, V. M.; FALCÃO, A. P.; GRIS, E. F.; BONIN, V.; BORDIGNON-LUIZ, M. T. Maturity of Cabernet Sauvignon berries from grapevines grown with two different training systems in a new grape growing region in Brazil. Ciencia e Investigación Agraria, Santiago, v.35, n.3, p.271-282, 2008.

FAVERO, A. C.; AMORIN de, D. A.; MOTA da, R. V.; SOUZA, C. R.; REGINA, M. A. Physiological responses and production of 'Syrah' vines as a function of training systems. Scientia Agricola, Piracicaba, v.67, n.3, p.267-273, 2010.

JONES, G. V. Climate and terroir: Impacts of climate variability and change on wine. In: MACQUEEN, R.W.; MEINERT, L.D. Fine Wine and Terroir-The Geoscience Perspective. $9^{\text {th }}$ ed. St. John's: Geological Association of Canada, 2006. 247p.

JUBILEU, B. da S.; SATO, A. J.; ROBERTO, S. R. Caracterização fenológica e produtiva das videiras 'Cabernet Sauvignon' e 'Alicante' (Vitis vinifera L.) produzidas fora de época, no norte do Paraná. Revista Brasileira de Fruticultura, Jaboticabal, v.32, n.2, p.451-462, 2010.

KENNEDY, J. A. Grape and wine phenolics: Observations and recent findings. Ciencia e Investigación Agraria, Santiago, v.35, n.2, p.107-120, 2008.

LEGAVE, J. M. Comment faire face aux changements climatiques en arboriculture fruitière ? Innovation Agronomiques, Lusignan, v.7, p.165-177, 2009.
LEGAVE, J. M.; DANILO, C.; GIOVANNINI, D.; OGER, R. Global warning in Europe and its impacts on floral bud phenology in fruit species. Acta Horticulturae, The Hague, n.838, p.21-26, 2009. Disponível em: <http://www.actahort.org/ books/838/838_1.htm>

LOPES, J.; EIRAS-DIAS, J. E.; ABREU, F.; CLÍMACO, P.; CUNHA, J. P.; SILVESTRE, J. Exigências térmicas, duração e precocidade de estados fenológicos de castas da coleção ampelográfica nacional. Ciência Técnica Vitivinícola, Dois Portos, v.23, n.1, p.61-71, 2008.

LOUARN, G.; DAUZAT, J.; LECOEUR, J.; LEBON, E. Influence of trellis system and shoot positioning on light interception and distribution in two grapevine cultivars with different architectures: an original approach based on 3D canopy modelling. Australian Journal of Grape and Wine Research, Adelaide, v.14, n.3, p.143-152, 2008.

LÜERS, J. Agraklimatologische und phänologische Auswertungen anhand ausgewählter Klimaindikatoren für das Mittlere Moseltal in Alfred-WegenerStiftung. Terra Nostra, Berlin, n.6, v.6, p.285-290, 2003.

MANDELLI, F.; MIELE, A.; RIZZON, L. A.; ZANUS, M. C. Efeito da poda verde na composição físico-química do mosto da uva Merlot. Revista Brasileira de Fruticultura, Jaboticabal, v.30, n.3, p.667-674, 2008.

MIELE, A.; RIZZON, L. A.; MANDELLI, F. Manejo do dossel vegetativo da videira e seu efeito na composição do vinho Merlot. Pesquisa Agropecuária Brasileira, Brasília, v.44, n.5, p.463-470, 2009.

ORLANDINI, S.; Di SEFANO, V.;LUCCHESINI, P.; PUGLISI, A. E.; BARTOLINI, G. Current trends of agroclimatic indices applied to grapevine in Tuscany (Central Italy). Quarterly Journal of the Hungarian Meteorological Service, Budapest, v.113, n.1-2, p.69-78, 2009.

SEGIN, B. Impact du changement climatique et adaptation de l'agriculture Impact of climate change and adaptation of agriculture. In : INRA. Mission 'Changement climatique et effet de serre',site Agroparc, domaine Saint-Paul. 2007. Disponivel em : <http://chaireunesco-vinetculture.ubourgogne .fr/Actes\%20clima/Actes/Article_Pdf/Seguin.pdf $>$. 
STOCK, M.; BADECK, F. ; GERSTENGARBE, HOPPMANN, D. ; KARTSCHALL, T. ; ÖSTERLE, H. ; WERNER, P. C. ; WODISNSKI, M. Perspektiven der Klimaänderung bis 2050 für den Weinbau in Deutschland. In: PIK. Report. Potsdam: Institut fuer Klimafolgenforschung, 2007. 132p.
ZANUS, M.; MANDELLI, F. Safra 2004 na Serra

Gaúcha: perspectiva de vinhos tintos de alta qualidade e de sabor mais intenso. 2004. 2p. Disponível em: $\quad$ http://www.cnpuv.embrapa.br/publica/ artigos/2004>. 